\title{
The Influence of Gender on Saudi Students Performance in the Undergraduate Surgical Examination
}

\author{
Abdulmohsen A. Al-Mulhim, Mohamed A. Elsharawy ${ }^{*}$, Naif Al Awad \\ Department of Surgery, University of Dammam, Al-Khobar, Kingdom of Saudi Arabia \\ Email: "elsharawya@yahoo.co.uk
}

Received December 5, 2011; revised January 16, 2012; accepted February 16, 2012

\begin{abstract}
The relationship between student gender and examination of medical knowledge and clinical competence has been assessed by a number of studies from western countries with controversial results. The aim of this study was to investigate if gender would make a difference on the performance of Arab medical students in the final certifying examination in surgery. Methods: This a cross-sectional study which was carried out at Department of Surgery, University of Dammam, Saudi Arabia over 3 years. The scores in each section and the total score of the final certifying examination of surgery were recorded for all sixth year students between 2008 and 2011. Differences between the scores of the female and male students in the written test and subjective examinations were assessed. Results: Six hundred and twenty students were involved in this study. Three hundred and fifty were male and 270 were female. Overall scores revealed that female medical students scored significantly better with lower failure rate compared to their male colleagues. Female students received significantly better scores than male in subjective tests. However, there was no significant difference between groups in written examination. Conclusion: There was no significant difference between male and female students in the written examination scores. However, female students performed better in subjective evaluations. Further studies are warranted to reveal the reasons behind this difference.
\end{abstract}

Keywords: Gender; Undergraduate Medical Students; Evaluation

\section{Introduction}

"Gender" refers to how differences between men and women are constructed in different cultures $[1,2]$. The relationship between student gender and examination of medical knowledge and clinical competence has been assessed by a number of studies [3,4]. The results of such studies have been a subject of controversy in the literature. Some reported no difference between male and female in any aspect of the grading scheme including oral and written multiple choice examination [5]. In contrast, others found female students outperformed male on both clinical evaluations and written examination [6]. In between the previous reports some found female students outperformed male in subjective evaluation with no difference between groups in multiple choice examination [7]. Even in these studies, if difference exists; is it true or it is a matter of bias [8]. Moreover, all the previous studies have been reported from western countries and this relation between gender and performance in medical examination has not been studied well in Arab medical schools. Gender inequality has been overlooked in Saudi Arabia for long time. The extension of these gender is-

"Corresponding author. sues into medical education and assessment has serious implications.

The aim of this study was to investigate if gender would make a difference on the performance of Saudi medical students in the final certifying examination in surgery.

\section{Methods}

This cross-sectional study was carried out at Department of Surgery, University of Dammam, Saudi Arabia over 3 years. The scores in each section and the total score of the final certifying examination of surgery were recorded for all sixth year students between 2008 and 2011. The students are usually admitted into medical faculty at age of 17 - 18 years directly after single sex high school. In the faculty of medicine, male and female students undergo teaching (lectures, bed side) and clinical examination in separate sections. However, both follow the same curriculum, the same faculty staffs are involved in teaching both groups and both have common MCQ questions. Most of the teaching staff are male. Assessment of the students was performed by describing the student's performance on clearly defined set of tasks (Criterion-Ref- 
erenced). However, assessment results were usually interpreted by both norm-referenced and criterion-referenced interpretation.

\subsection{Components of the Examination}

Half of our learning outcome was assessed by a written test. The other half of assessment was by subjective performance assessment. The written test was a selected response test which consists of 100 questions of interpretive MCQ exercise. It covers all intended learning outcome. All tests are assessed by item analysis to check difficulty index, discrimination index and percentage of reliability.

For performance tests, ten percent is performed by daily continuous assessment. The rest is divided equally between a restricted performance test by OSCE and extended performance assessment by a clinical examination involving one long clinical case.

The total score was divided into 5 grades; A ( $>90 \%)$, B $(80 \%-90 \%)$, C $(70 \%-80 \%)$, D $(60 \%-70 \%)$, F $(<$ $60 \%)$.

\subsection{Statistical Analysis}

Chi square test or Fisher's exact test was used as appropriate to assess differences in failure rate between both groups. Difference between grades was assessed using Mann Whitney test. Other results were summarized using descriptive statistics. These were presented as mean \pm SD and compared using Student t-test. Significance was set at $\mathrm{p} \leq 0.05$ for all comparisons. All statistical analyses were performed with the aid of SPSS 15 (SPSS Inc, Chicago, IL) software.

\section{Results}

Six hundred and twenty students were involved in this study. Three hundred and fifty were male and 270 were female. The qualities of the MCQ tests were very good over the study period. Overall scores revealed that female medical students scored significantly better $(p \leq 0.001)$ with lower failure rate $(p=0.004)$ compared to their male colleagues Table 1. However there was insignificant difference between both groups as regards grading (male students grades F, D, C, B, A were 17 (6\%), 71 $(20 \%), 175(50 \%), 84(24 \%)$ and $3(1 \%)$ respectively compared to $2(1 \%), 26(10 \%), 151(56 \%), 88(32 \%)$ and $3(1 \%)$ in female students, $\mathrm{p}=0.754)$ Figure 1 . When content analysis was performed, female students received significantly better scores than male in total and in all components of performance subjective tests (continuous assessment, $\mathrm{p} \leq 0.001$, OSCI $\mathrm{p} \leq 0.001$ and clinical examination $\mathrm{p} \leq 0.001$ ) Table 2. However, there was no significant difference between both groups as regard written examination $(\mathrm{P}=0.081)$ Table 2 .

\section{Discussion}

Assessment of students emphasizes the principles and practices of achievement that contribute to more effective classroom instruction and improved student learning. It also determines the extent to which students are achieving the intended learning outcomes of instruction. To perform an effective student assessment [9] for our surgical course, many measures were done including using variety of assessment procedures, adequate sampling of student performance in every components etc.

Table 1. Mean percentage \pm SD of the scores of the total and all items scores of final certifying examination tests for female and male students.

\begin{tabular}{lccc}
\hline \multicolumn{1}{c}{ Components } & $\begin{array}{c}\text { Female students } \\
(\text { No. 350) }\end{array}$ & $\begin{array}{c}\text { Male students } \\
(\text { No. 270) }\end{array}$ & P value \\
\hline Written examination & $69.56 \pm 9.13$ & $68.17 \pm 10.37$ & 0.081 \\
Performance tests & $83.73 \pm 6.14$ & $78.94 \pm 9.05$ & $<0.001$ \\
Total score & $76.65 \pm 5.88$ & $73.55 \pm 8.18$ & $<0.001$ \\
Failure rate & $2(0.5 \%)$ & $17 /(6 \%)$ & 0.004 \\
\hline
\end{tabular}

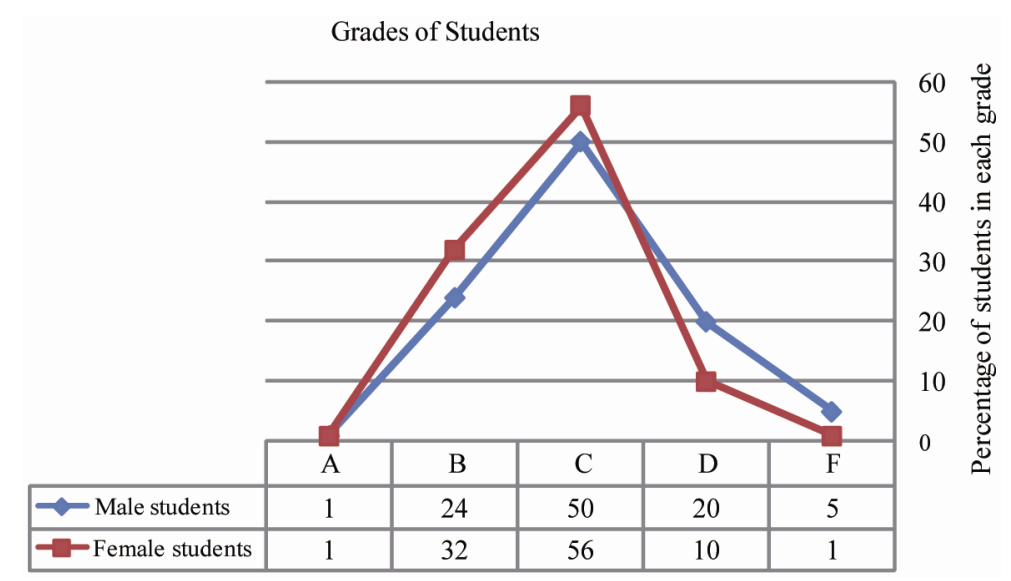

Figure 1. Percentage of grading of final certifying examination tests in female and male students. 
Table 2. Mean percentage \pm SD of the scores of the performance tests in female and male students.

\begin{tabular}{lccc}
\hline \multicolumn{1}{c}{ Components } & Female students & Male students & P value \\
\hline Continuous assessment & $87.57 \pm 5.79$ & $82.04 \pm 9.38$ & $<0.001$ \\
OSCE & $82.05 \pm 10.76$ & $77.83 \pm 12.67$ & $<0.001$ \\
Clinical examination & $82.3 \pm 8.22$ & $77.86 \pm 11.63$ & $<0.001$ \\
Total & $83.73 \pm 6.14$ & $78.94 \pm 9.05$ & $<0.001$ \\
\hline
\end{tabular}

The results of our study agree with previous studies which showed that females significantly outperformed male. The better academic achievement by female students in medicine in both this study and ours was largely believed due to subjective elements [10]. On the other hand other studies showed higher performance of male students using multiple choice questions [11].

Although female students in the present study showed higher and significant total scores, these scores were not consistently higher in sub-domains. While female students did better in performance tests, there was no significant difference in written examination. The reasons of this difference are still vague. In a study on medical school applicants in the United States, females were found to have significantly higher emotional intelligence (maturity, compassion, morality, sociability and cam disposition) as compared to males [12]. There is evidence that at the age of 18 years, the maturation of the brain of male lag behind the brains of female by 3 years [13] and male can be considered to lag females by 2 years in physical maturation [14]. However at age of 24 years both genders have completed their maturation process $[13,15]$. All our students at the time of the final certifying examination exceed 24 years.

We noticed also that female students have better attendance in hospital than male students. Previous studies have showed that female are more intrinsically motivated and less externally motivated [16]. This may explain that female medical students perform better than male medical students specially in clinical examination $[17,18]$. Previous studies suggest also that female students are better at communicating successfully under exam conditions [19]. Moreover, it was established that female students were more patient centered than doctor-centered compared to males [19].

Gender bias is sometimes taught implicitly. The better scores in clinical examination for female students could be attributed to leniency [20,21]. There is some evidence that combination of a male examiner/male patient to female students gave a higher score than male/male to male patient [19]. Most of our examiners and patients chosen for clinical examination were male. Some studies showed, despite of sitting in the same classroom, reading the same textbook, listening to the same teacher, boys and girls receive very different educations [22].
Our study and others [23] raised inconvenient question regarding the validity of subjective evaluation of medical students by faculty. While female students perform better, although not always significant, than male students, this did affect overall grading.

The present study has several limitations. The study was carried out in one institution and assessing one subject only. We also did not measure the educational background of students. Some of students studied secondary school in high standard American and English schools. Others studied in Arabic schools.

\section{Conclusion}

There was no significant difference between male and female students in the written examination scores. However, female students performed better in subjective evaluations. Further studies are warranted to address the reasons behind this difference.

\section{REFERENCES}

[1] A. Hammarstrom, "The Integration of Gender in Medical Research, Education-Obstacles and Possibilities from a Nordic Perspective," In: L. Manderson, Ed., Teaching Gender, Teaching Women's Health. Case Studies in Medical and Health Science Education, The Haworth Medical Press, Binghamton, 2003, pp. 121-133.

[2] V. W. Pinn, "Sex and Gender Factors in Medical Studies. Implications for Health and Clinical Practice," Journal of the American Medical Association, Vol. 289, No. 4, 2003, pp. 397-400. doi:10.1001/jama.289.4.397

[3] S. S. Meit, H. T. Meit and V. Yasek, "Personality Traits of Incoming WVU Medical Students: Phase I Gender Findings," West Virginia Medical Journal, Vol. 95, 1999, pp. 123-126.

[4] J. A. Richman and J. A. Flaherty, "Gender Differences in Medical Student Distress: Contributions of Prior Socialization and Current Role-Related Stress," Social Science \& Medicine, Vol. 30, No. 7, 1990, pp. 777-787. doi:10.1016/0277-9536(90)90201-3

[5] F. F. Holmes, G. E. Holmes and R. Hassanein, "Performance of Male and Female Medical Students in a Medicine Clerkship," Journal of the American Medical Association, Vol. 239, 1978, pp. 2259-2262. doi:10.1001/jama.1978.03280480051020

[6] W. C. Plauché and J. M. Miller Jr., "Performances of Female Medical Students in an Obstetrics and Gynecology Clerkship," Journal of Medical Education, Vol. 61, 1986, pp. 323-325.

[7] P. M. Krueger, "Do Women Medical Students Outperform Men in Obstetrics and Gynecology?" Academic Medicine, Vol. 73, No. 1, 1998, pp. 101-102. doi:10.1097/00001888-199801000-00021

[8] J. K. Dorsey and J. A. Colliver, "Effect of Anonymous Test Grading on Passing Rates as Related to Gender and Race," Academic Medicine, Vol. 70, 1995, pp. 321-323. 


\section{doi:10.1097/00001888-199504000-00017}

[9] N. E. Gronlund, "Nature of Student Assessment," In: A. E. Burvikovs and K. Hopkins, Eds., Assessment of Student Achievement, 8th Edition, Pearson, Boston, 2006, pp. 14-30.

[10] C. Castagnetti and L. Rosti, "Effort Allocation in Tournaments: The Effect of Gender on Academic Performance in Italian Universities," Economics of Education Review, Vol. 28, 2008, pp. 3357-3379.

[11] G. Margo, "Gender Differences in Multiple Choice Assessment," Record No. 10, 1993. http:erl.canberra.edu.au./public/adt-AUC20050218.14100 5

[12] R. M. Carrothers, S. W. Gregory Jr. and T. J. Gallagher, "Measuring Emotional Intelligence of Medical School Applicants," Academic Medicine, Vol. 75, No. 5, 2000, pp. 456-463. doi:10.1097/00001888-200005000-00016

[13] R. Kusurkar, C. Kruitwagen, O. Ten Cate and G. Croiset, "Effects of Age, Gender and Educational Background on Strength of Motivation for Medical School," Advances in Health Sciences Education, Vol. 15, No. 3, 2010, pp. 303-313. doi:10.1007/s10459-009-9198-7

[14] J. M. Tanner, R. H. Whitehouse, E. Marubini and L. F. Resele, "The Adolescent Growth Spurt of Boys and Girls of the Harpenden Growth Study," Annal of Human Biology, Vol. 3, No. 2, 1976, pp. 109-126. doi: $10.1080 / 03014467600001231$

[15] L. Steinberg and E. Cauffman, "Maturity of Judgment in Adolescence: Psychosocial Factors in Adolescent Decision Making," Law and Human Behavior, Vol. 20, No. 3, 1996, pp. 249-272. doi:10.1007/BF01499023

[16] R. J. Vallerand and R. Bissonnette, "Intrinsic, Extrinsic, and a Motivational Style as Predictors of Behavior: A Prospective Study," Journal of Personality, Vol. 60, No.
3, 1992, pp. 599-620. doi:10.1111/j.1467-6494.1992.tb00922.x

[17] J. Yates, J. Smith, D. James and E. Ferguson, "Should Applicants to Nottingham University Medical School Studies a Non-Science A-level? A Cohort Study," BMC Medical Education, Vol. 9, 2009, pp. 5-13. doi:10.1186/1472-6920-9-5

[18] C. M. Wiskin, T. F. Allan and J. R. Skelton, "Gender as a Variable in the Assessment of Final Year Degree-Level Communication Skills," Medical Education, Vol. 38, No. 2, 2004, pp. 129-137. doi:10.1111/j.1365-2923.2004.01746.x

[19] E. Krupat, C. M. Hiam, M. Z. Fleming and P. Freeman, "Patient-Centeredness and Its Correlates among First Year Medical Students," International Journal of Psychiatry in Medicine, Vol. 29, No. 3, 1999, pp. 347-356. doi:10.2190/DVCQ-4LC8-NT7H-KE0L

[20] R. Axelson, "Assessing Implicit Gender Bias in Medical Student Performance Evaluation," Evaluation \& the Health Professions, Vol. 33, 2010, pp. 365-385.

[21] D. Sadker and M. Sadker, "Failing at Fairness: How Our Schools Cheat Girls," Simon \& Schuster Inc., Toronto, 1994.

[22] J. L. Bienstock, S. Martin, W. Tzou and H. E. Fox, "Medical Students' Gender Is a Predictor of Success in the Obstetrics and Gynecology Basic Clerkship," Teaching and Learning in Medicine, Vol. 14, No. 4, 2002, pp. 240-243. doi:10.1207/S15328015TLM1404 7

[23] I. Haq, J. Higham, R. Morris and J. Dacre, "Effect of Ethnicity and Gender on Performance in Undergraduate Medical Examinations," Medical Education, Vol. 39, No. 11, 2005, pp. 1126-1128. doi:10.1111/j.1365-2929.2005.02319.x 